\title{
Electrostatic Self-Assembly and Covalent Fixation with Cationic and Anionic Telechelic Precursors for New Loop and Branch Polymer Topologies ${ }^{\dagger}$
}

\author{
Kaoru Adachi, Hiroyasu Irie, Takeya Sato, Akiko Uchibori, \\ Mitsuru Shiozawa, and Yasuyuki Tezuka*
}

Department of Organic and Polymeric Materials, Tokyo Institute of Technology, O-okayama, Meguro-ku, Tokyo 152-8552, Japan

Received September 11, 2005; Revised Manuscript Received October 4, 2005

\begin{abstract}
An electrostatic self-assembly of cationic and anionic polymer precursors and subsequent covalent fixation has been performed to construct a series of loop and branch polymer topologies. The process employed the two cationic polymer precursors (1a and 1b) having two pyrrolidinium salt groups either at both chain ends (1a) or at the designated interior positions (1b), and the two anionic counterparts (2a and $\mathbf{2 b}$ ) having two carboxylate groups either at both chain ends (2a) or at a single chain end (2b). A series of electrostatic polymer-polymer self-assemblies have been prepared by the combination of cationic and anionic precursors, i.e., $\mathbf{1 a} / \mathbf{2 a}, \mathbf{1} \mathbf{a} / \mathbf{2} \mathbf{b}$, and $\mathbf{1 b} / \mathbf{2} \mathbf{a}$, respectively, through simple coprecipitation of the precursor polymer mixture into an aqueous medium. The subsequent covalent conversion of the electrostatically self-assembled products by heating under dilution could produce a ring polymer from $\mathbf{1 a} / \mathbf{2 a}$, a tadpole polymer from $\mathbf{1 a} / \mathbf{2 b}$, and a two-tail tadpole, having a loop and two branches, polymer from $\mathbf{1 b} / \mathbf{2 a}$, respectively.
\end{abstract}

\section{Introduction}

The chain-linking reaction by telechelic precursors, possessing reactive groups typically at the two ends of a linear polymer chain, has now been a routine practice for the production of a wide variety of polymer materials. ${ }^{1-4}$ A remarkable progress has been observed during recent decades in the structural refinement of telechelic polymers, in which exact numbers of specific reactive groups are precisely positioned at the designated locations of not only linear but also branched and even loop polymer chains. ${ }^{5-9}$ Thus, in principle, the inter- and intramolecular chain-linking process using appropriate telechelic precursors could make a variety of complex polymer architectures with high precision. In practice, however, such a process has been an ongoing challenge because it must overcome the kinetic circumvention by the inherent low concentration of a small number of reactive groups at the long polymer chain, or by the exclusion volume effect and steric hindrance occurring in the reaction between polymers. ${ }^{10}$ Thus, a new organic chemistry process, such as "click chemistry", has been continuously applied to achieve effective linking of polymer precursors. ${ }^{11,12}$ The polymeric loop formation by a bimolecular chain-linking process is considered as a formidable challenge as well because the reaction should be conducted under dilution, thus further lowering the concentration of reactive groups, to suppress the uncontrolled chain extension.

We have employed an electrostatic interaction to attract functional groups of telechelic precursors even at low overall concentration and to achieve the effective chain-linking reaction between them. ${ }^{13}$ Thus, electrostatically self-assembled polymer intermediates have been prepared from cationic telechelic precursors having

\footnotetext{
The paper is dedicated to Professor Shohei Inoue in honor of his 70th birthday.

* Corresponding author. E-mail: ytezuka@o.cc.titech.ac.jp.
}

modestly strained cyclic ammonium salt groups and anionic counterparts having carboxylate groups, and they have been subjected to the covalent fixation by the ring-opening reaction of cyclic ammonium groups by carboxylate anions. A series of block, graft, and network copolymers have been produced effectively. ${ }^{14-18}$

A wide variety of small carboxylate counteranions have been introduced purposely on the linear or starshaped cationic telechelic precursors. ${ }^{19-22}$ Under appropriate dilution, these polymer precursors tend to form unique electrostatic self-assemblies in which the cations and anions balance the charges. The subsequent ring-opening reaction of cyclic ammonium salt groups by carboxylate counteranions at elevated temperatures could produce a variety of covalently linked polymer products having unique loop topologies, including a simple ring polymer ${ }^{23-26}$ optionally having functional groups at predetermined positions (cyclic macromono$\operatorname{mer}^{27}$ and kyklo-telechelics ${ }^{28}$ ), three dicyclic polymers having either 8-, $\theta$-, and manacle topologies, ${ }^{23,29-31}$ as well as a tricyclic trefoil-shaped polymer. ${ }^{23}$ Even such a complex multicyclic, i.e., a doubly fused tricyclic, $\delta$-graph topology, polymer has been effectively synthesized from an 8-shaped polymer precursor having allyl groups at designated positions. ${ }^{32}$

Tadpole-type polymers are another important class of topological polymers having a single loop and a variety of branches (Scheme 1). ${ }^{33-36}$ A tadpole polymer, optionally having functional groups at the designated positions, has been effectively produced so far by taking advantage of the dynamic equilibrium in a mixture of electrostatically self-assembled polymer precursors. ${ }^{34}$ Besides, a twin-tail tadpole polymer has been obtained from an interiorly functionalized precursor carrying a bifunctional carboxylate counteranion. ${ }^{37}$

In the present study, we have applied the electrostatic self-assembly and covalent fixation process in dilution by using a series of cationic polymer precursors and anionic counterparts (thus polymeric carboxylate coun- 
Scheme 1. A Series of Tadpole Constructions

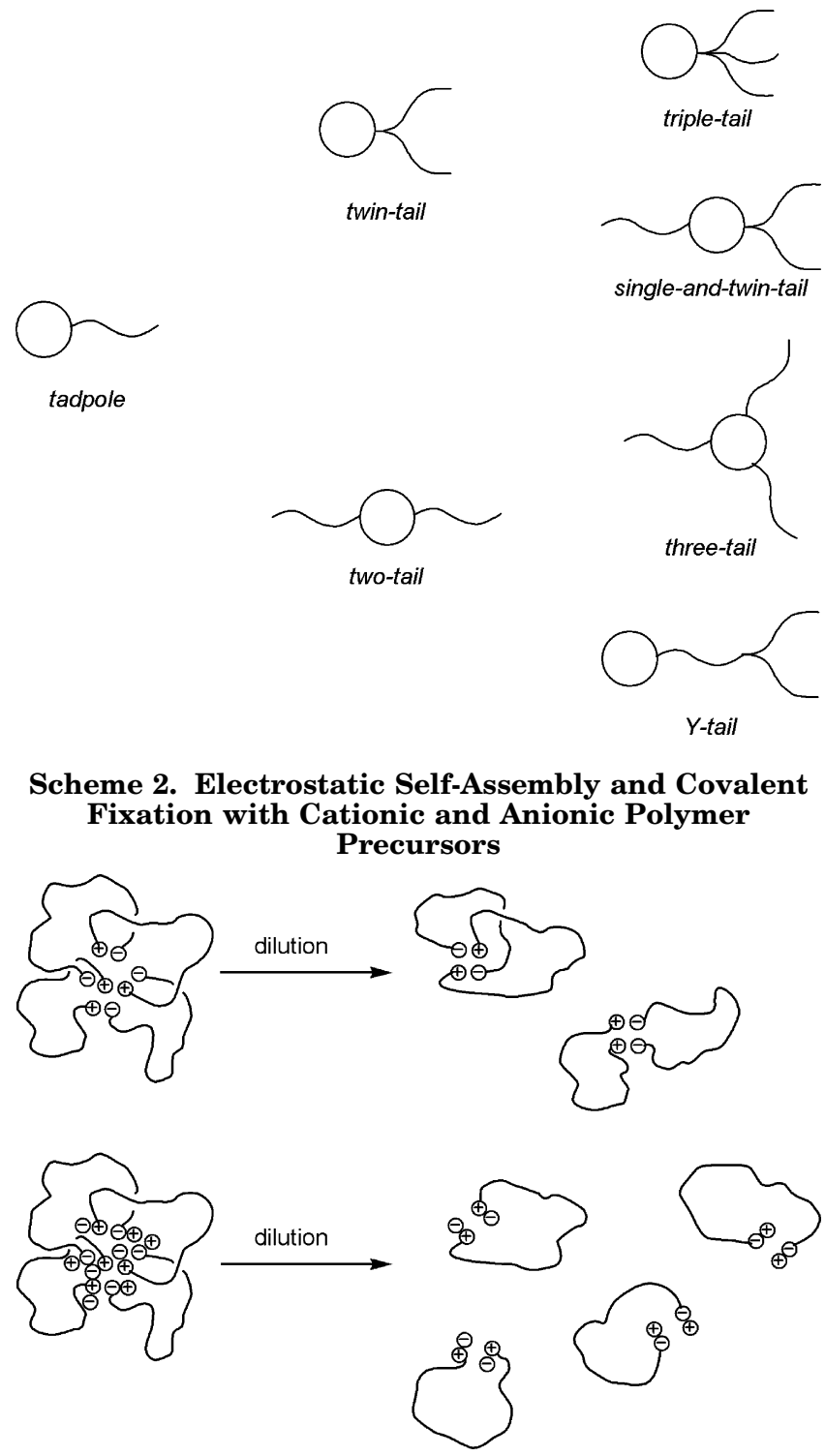

teranions) for the effective construction of a variety of loop and branch polymer topologies, including a twotail tadpole construction, ${ }^{38,39}$ which is not directly obtainable by the dilution process using the electrostatically self-assembled polymer precursor carrying small counteranions. We anticipated that electrostatically assembled polymer precursors are obtainable by the coprecipitation of a cationic and an anionic telechelic precursors by removing small anionic and cationic counterions initially accompanied with the telechelic precursors. The subsequent dilution will produce a unique self-assembly, in which cationic and anionic polymer precursors are combined to balance the charges. This is contrary to the mixture of the cationic and anionic telechelic precursors keeping small anionic and cationic counterions, where the dilution causes the complete de-assembly to give a unimolecular polymer species (Scheme 2).

\section{Experimental Section}

Preparation of Polymer Precursors. A poly(THF) having $N$-phenylpyrrolidinium salt end groups $\left(\mathbf{1 a}, M_{\mathrm{p}}(\mathrm{SEC})=\right.$ 5500 and 5600 , PDI $=1.20$ and 1.10 , respectively) and an interiorly functionalized (eso-telechelic) poly(THF) having pyrrolidinium salt groups $\left(\mathbf{1 b}, M_{\mathrm{p}}(\mathrm{SEC})=8400, \mathrm{PDI}=1.04\right)$ were prepared by the method detailed before. ${ }^{23,24,37}$
A poly(THF) having carboxylate end groups $\left(\mathbf{2 a}, M_{\mathrm{p}}(\mathrm{SEC})\right.$ $=4400$ and 2500 , PDI $=1.18$ and 1.22 , respectively), and a poly (THF) having a dicarboxylate end group $\left(\mathbf{2 b}, M_{\mathrm{p}}(\mathrm{SEC})=\right.$ $2800, \mathrm{PDI}=1.15$ ) were prepared by the end-capping reaction of a bifunctionally and monofunctionally living poly(THF) with an aniline derivative possessing either one or two methyl ester groups, respectively, and subsequent hydrolysis/quaternization reactions. Thus, for the preparation of $\mathbf{2 a}$, a bifunctionally living poly(THF), prepared with $100 \mathrm{~mL}$ of dry THF and trifluoromethanesulfonic anhydride $(416 \mathrm{mg}, 1.48 \mathrm{mmol}$ ) as an initiator at $25{ }^{\circ} \mathrm{C}$ for $8 \mathrm{~min}$, was allowed to react with methyl 4-aminobenzoate ( $3.84 \mathrm{~g}, 25.3 \mathrm{mmol}$, in $10 \mathrm{~mL}$ of THF). The crude product was recovered by precipitation into icecooled $\left(<5{ }^{\circ} \mathrm{C}\right)$ hexane, and the residual methyl 4 -aminobenzoate was removed by the repeated centrifugation $(4000 \mathrm{rpm}$ for $10 \mathrm{~min}$ ) from the chloroform solution. The product, poly(THF) having methyl benzoate end groups, was finally isolated by precipitation into $0.2 \mathrm{M} \mathrm{HCl} \mathrm{aq}(500 \mathrm{~mL})$. The yield was $2.49 \mathrm{~g}\left({ }^{1} \mathrm{H}\right.$ NMR spectrum is shown in S-Figure 1 in Supporting Information). The subsequent alkaline hydrolysis of methyl benzoate end groups was performed as follows. Into a THF solution of the ester-ended poly(THF) $(500 \mathrm{mg}$ in $13 \mathrm{~mL})$ was added 50 wt $\%$ of $\mathrm{NaOH}$ aq $(4 \mathrm{~mL})$, ethanol $(2 \mathrm{~mL})$, and water $(10 \mathrm{~mL})$, and the reaction was allowed to proceed at $90{ }^{\circ} \mathrm{C}$ for $72 \mathrm{~h}$. The product, poly(THF) having carboxylic acid end groups, was recovered after precipitation into $0.2 \mathrm{M} \mathrm{HCl} \mathrm{aq}$ $(500 \mathrm{~mL})$, by the addition of the solution with $0.1 \mathrm{M} \mathrm{HCl} \mathrm{aq}$ $(25 \mathrm{~mL})$, water $(50 \mathrm{~mL})$, and THF $(50 \mathrm{~mL})$. The carboxylic acidended poly(THF) was isolated by filtration and dried in vacuo for $2 \mathrm{~h}$. The yield was $469 \mathrm{mg}\left({ }^{1} \mathrm{H}\right.$ NMR spectrum is shown in S-Figure 2 in Supporting Information). Finally, a poly(THF) having carboxylate end groups (2a) was obtained by quaternization of the carboxylic acid end groups. Thus, into a THF $(3 \mathrm{~mL})$ solution of the carboxylic acid-ended poly(THF) (125 $\mathrm{mg}$ ), slightly excess of tetra- $n$-butylammonium hydroxide (10 wt \% in methanol, $82 \mu \mathrm{L}, 0.32 \mu \mathrm{mol}$ ) was added and then dried in vacuo for up to $6 \mathrm{~h}$. The yield of $\mathbf{2 a}$ was 93 mg. ${ }^{1} \mathrm{H}$ NMR: $\delta 0.96\left(\mathrm{t}, J=7.2 \mathrm{~Hz}, 24 \mathrm{H}, \mathrm{NCH}_{2} \mathrm{CH}_{2} \mathrm{CH}_{2} \mathrm{CH}_{3}\right.$ ), $1.41\left(\mathrm{~m}, 16 \mathrm{H}, \mathrm{NCH}_{2} \mathrm{CH}_{2} \mathrm{CH}_{2} \mathrm{CH}_{3}\right), 1.50-1.85\left(\mathrm{~m}, \mathrm{CH}_{2} \mathrm{CH}_{2} \mathrm{O}\right.$, $\mathrm{NCH}_{2} \mathrm{CH}_{2} \mathrm{CH}_{2} \mathrm{CH}_{3}$ ), 3.20-3.60 (m, $\mathrm{CH}_{2} \mathrm{CH}_{2} \mathrm{O}, \mathrm{NCH}_{2} \mathrm{CH}_{2} \mathrm{CH}_{2}-$ $\left.\mathrm{CH}_{3}\right), 6.47-6.55\left(\mathrm{~d}, J=8.1 \mathrm{~Hz}, 4 \mathrm{H}, \mathrm{Ar}-\mathrm{H}\right.$ meta to $\left.\mathrm{CO}_{2}\right), 7.91-$ $7.98\left(\mathrm{~d}, J=8.4 \mathrm{~Hz}, 4 \mathrm{H}, \mathrm{Ar}-\mathrm{H}\right.$ ortho to $\left.\mathrm{CO}_{2}\right)$.

A poly(THF) having a dicarboxylate end group (2b) was prepared by a similar procedure. Thus, a poly(THF) having a dimethyl isophthalate end group was obtained from the endcapping reaction of a monofunctionally living poly(THF), prepared with $50 \mathrm{~mL}$ of dry THF and methyl trifluoromethanesulfonate $(170 \mathrm{mg}, 1.04 \mathrm{mmol})$ as an initiator at $25{ }^{\circ} \mathrm{C}$ for 12 $\mathrm{min}$, with dimethyl 5-aminoisophthalate $(1.06 \mathrm{~g}, 5.07 \mathrm{mmol})$. The subsequent end-group transformation reactions were conducted as in the preparation of $\mathbf{2 a} .{ }^{1} \mathrm{H}$ NMR spectra of ester-ended and carboxylic acid-ended precursors are shown in S-Figures 3 and 4, respectively, in Supporting Information. The yield of $\mathbf{2 b}$, having a dicarboxylate end group, was 967 mg. ${ }^{1} \mathrm{H}$ NMR: $\delta 0.94\left(\mathrm{t}, J=7.1 \mathrm{~Hz}, 24 \mathrm{H}, \mathrm{NCH}_{2} \mathrm{CH}_{2} \mathrm{CH}_{2} \mathrm{CH}_{3}\right)$, $1.36\left(\mathrm{~m}, 16 \mathrm{H}, \mathrm{NCH}_{2} \mathrm{CH}_{2} \mathrm{CH}_{2} \mathrm{CH}_{3}\right), 1.50-1.75\left(\mathrm{~m}, \mathrm{CH}_{2} \mathrm{CH}_{2} \mathrm{O}\right.$ $\left.\mathrm{NCH}_{2} \mathrm{CH}_{2} \mathrm{CH}_{2} \mathrm{CH}_{3}\right), 3.13\left(\mathrm{t}, \mathrm{J}=8.1 \mathrm{~Hz}, 16 \mathrm{H}, \mathrm{NCH}_{2} \mathrm{CH}_{2} \mathrm{CH}_{2-}\right.$ $\left.\mathrm{CH}_{3}\right), 3.32\left(\mathrm{~s}, 3 \mathrm{H}, \mathrm{CH}_{3} \mathrm{O}\right), 3.30-3.55\left(\mathrm{~m}, \mathrm{CH}_{2} \mathrm{CH}_{2} \mathrm{O}\right), 7.35(\mathrm{~s}$, $2 \mathrm{H}$, Ar-H ortho to $\mathrm{NH}$ ), 7.94 (s, $1 \mathrm{H}$, Ar-H para to $\mathrm{NH}$ ).

Electrostatic Self-Assembly of Cationic and Anionic Telechelic Precursors. A series of electrostatic self-assemblies from cationic and anionic telechelic precursors, i.e., $\mathbf{1 a} / \mathbf{2 a}, \mathbf{1 a} / \mathbf{2} \mathbf{b}$, and $\mathbf{1} \mathbf{b} / \mathbf{2} \mathbf{a}$, were prepared by a coprecipitation procedure. The preparation of $\mathbf{1} \mathbf{a} / \mathbf{2 a}$ is described below as a typical example. An equimolar amount of telechelic precursors $1 \mathbf{a}(125 \mathrm{mg}, 0.022 \mathrm{mmol})$, carrying triflate counteranions, and 2a (88 mg, $0.023 \mathrm{mmol}$ ), carrying tetra- $n$-butylammonium countercations, were dissolved in THF $(2.0 \mathrm{~mL})$, and the solution was added dropwise into ice-cooled $\left(<5{ }^{\circ} \mathrm{C}\right)$ water under vigorous stirring. After $1 \mathrm{~h}$, the precipitated electrostatic polymer-polymer assembly $(\mathbf{1} \mathbf{a} / \mathbf{2 a})$ was collected by filtration and dried in vacuo for $2 \mathrm{~h}$ (148 $\mathrm{mg}, 72 \%$ yield). In a similar manner, the self-assemblies $\mathbf{1 a} / \mathbf{2 b}(93 \%$ yield) and $\mathbf{1 b} / \mathbf{2 a}(96 \%$ yield) were obtained. 
Scheme 3. Cationic and Anionic Telechelic Precursors
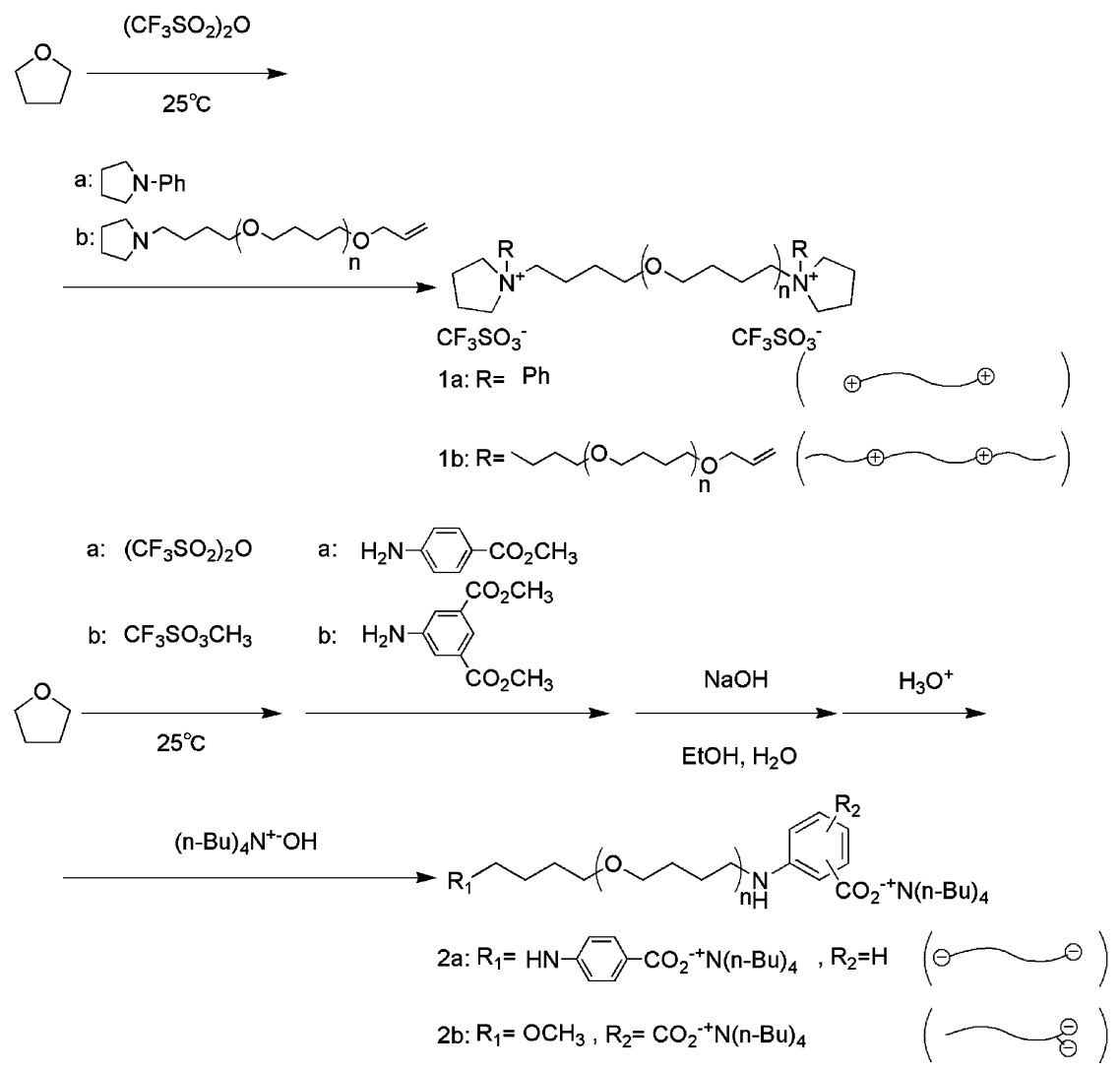

Scheme 4. Construction of Loop and Branch Polymer Topologies by Electrostatic Self-Assembly and Covalent Fixation with Cationic and Anionic Telechelic Precursors

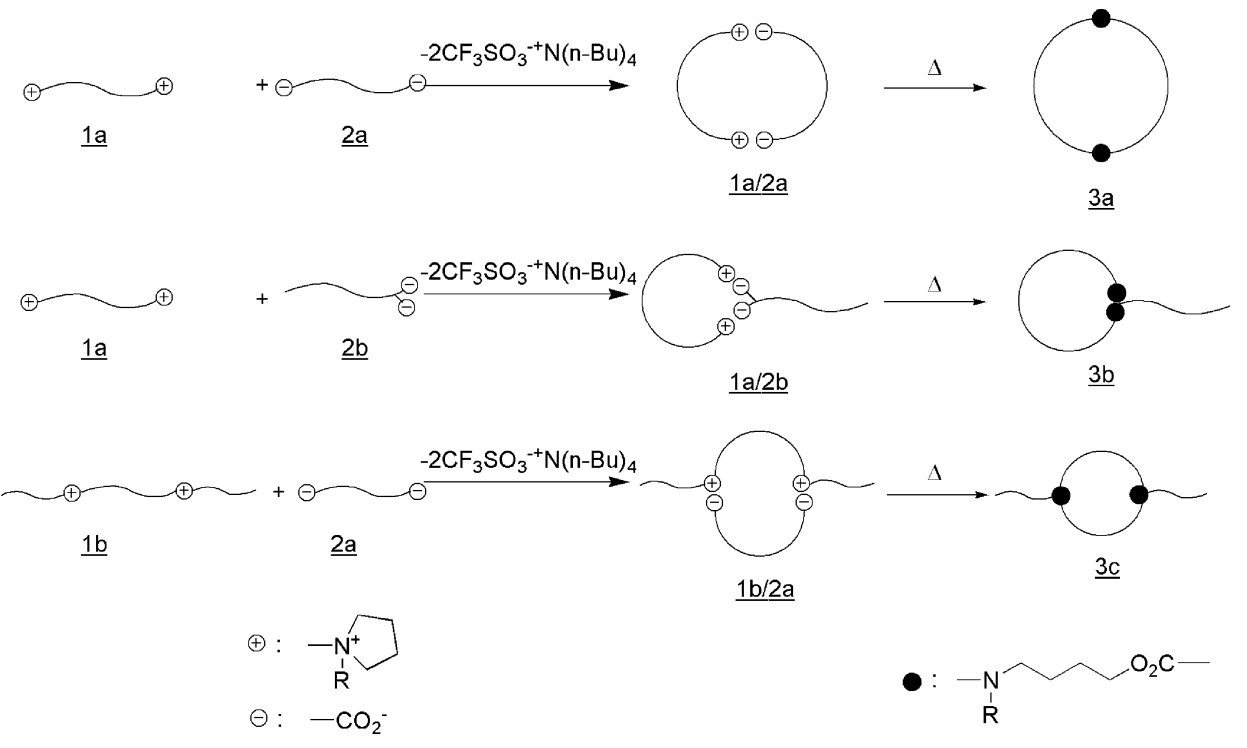

1a/2a: ${ }^{1} \mathrm{H}$ NMR (300 $\left.\mathrm{MHz} \mathrm{CDCl}_{3}\right): \delta$ 1.30-1.95 (m, $\left.\mathrm{CH}_{2} \mathrm{CH}_{2} \mathrm{O}\right), 1.98-2.08\left(\mathrm{~m}, 4 \mathrm{H}\right.$, endo- $\left.\mathrm{NCH}_{2} \mathrm{CH}_{2}\right), 2.10-2.72(\mathrm{~m}$, $4 \mathrm{H}$, exo- $\left.\mathrm{NCH}_{2} \mathrm{CH}_{2}\right), 3.10-3.75\left(\mathrm{~m}, \mathrm{CH}_{2} \mathrm{CH}_{2} \mathrm{O}\right), 4.03-4.20$ (m, $4 \mathrm{H}$, endo- $\left.\mathrm{NCH}_{2}\right), 4.65-4.75\left(\mathrm{~m}, 4 \mathrm{H}\right.$, exo-NCH$\left.{ }_{2}\right), 6.53(\mathrm{~d}, \mathrm{~J}=$ $8.4 \mathrm{~Hz}, 4 \mathrm{H}, \mathrm{Ar}-\mathrm{H}$ meta to $\mathrm{CO}_{2}$ ), 7.50-7.75 (m, 10H, NPh), 7.95 (d, $J=8.4 \mathrm{~Hz}, 4 \mathrm{H}, \mathrm{Ar}-\mathrm{H}$ ortho to $\mathrm{CO}_{2}$ ).

1a/2b: ${ }^{1} \mathrm{H}$ NMR (300 $\left.\mathrm{MHz}^{\mathrm{CDCl}}{ }_{3}\right): \delta$ 1.30-1.85 (m, $\mathrm{CH}_{2} \mathrm{CH}_{2} \mathrm{O}$ ), 1.93-2.05 (m, $4 \mathrm{H}$, endo- $\left.\mathrm{NCH}_{2} \mathrm{CH}_{2}\right), 2.30-2.40$ (m, $4 \mathrm{H}$, exo- $\left.\mathrm{NCH}_{2} \mathrm{CH}_{2}\right), 3.10-3.60\left(\mathrm{~m}, \mathrm{CH}_{2} \mathrm{CH}_{2} \mathrm{O}\right), 3.94-4.10(\mathrm{~m}$, $4 \mathrm{H}$, endo- $\left.\mathrm{NCH}_{2}\right), 4.25-4.49\left(\mathrm{~m}, 4 \mathrm{H}\right.$, exo- $\left.\mathrm{NCH}_{2}\right), 7.42(\mathrm{~s}, 2 \mathrm{H}$, Ar-H ortho to NH), 7.45-7.70 (m, 10H, NPh), 8.14 (s, $1 \mathrm{H}, \mathrm{Ar}-\mathrm{H}$ para to $\mathrm{NH})$.

1b/2a: ${ }^{1} \mathrm{H}$ NMR (300 $\left.\mathrm{MHz} \mathrm{CDCl}_{3}\right)$ : $\delta$ 1.10-2.30 (m, $\left.\mathrm{CH}_{2} \mathrm{CH}_{2} \mathrm{O}\right), 2.45-2.63\left(\mathrm{~m}, 8 \mathrm{H}, \mathrm{NCH}_{2} \mathrm{CH}_{2}\right), 3.05-3.85(\mathrm{~m}$,
$\mathrm{CH}_{2} \mathrm{CH}_{2} \mathrm{O}$ ), 3.94-3.97 (d, $\mathrm{J}=5.4 \mathrm{~Hz}, 4 \mathrm{H}, \mathrm{CH}_{2}=\mathrm{CHCH}_{2}$ ), 5.10$5.30\left(\mathrm{~m}, 4 \mathrm{H}, \mathrm{CH}_{2}=\mathrm{CHCH}_{2}\right), 5.80-5.96\left(\mathrm{~m}, 2 \mathrm{H}, \mathrm{CH}_{2}=\mathrm{CHCH}_{2}\right)$, $6.53\left(\mathrm{~d}, J=8.4 \mathrm{~Hz}, 4 \mathrm{H}, \mathrm{Ar}-\mathrm{H}\right.$ meta to $\left.\mathrm{CO}_{2}\right), 7.87$ (d, $J=7.5$ $\mathrm{Hz}, 4 \mathrm{H}, \mathrm{Ar}-\mathrm{H}$ ortho to $\mathrm{CO}_{2}$ ).

Covalent Conversion of Electrostatic Self-Assembly Between Cationic and Anionic Telechelic Precursors. A series of electrostatic self-assemblies with a variety of combinations of cationic and anionic telechelic precursors, i.e., $\mathbf{1 a} / \mathbf{2 a}, \mathbf{1} \mathbf{a} / \mathbf{2} \mathbf{b}$, and $\mathbf{1 b} / \mathbf{2 a}$, were dissolved either in THF (for $\mathbf{1 a} / \mathbf{2 a}$ and $\mathbf{1 a} / \mathbf{2 b}$ ) or in toluene (for $\mathbf{1 b} / \mathbf{2 a}$ ) at various dilutions $(0.1-1.0 \mathrm{~g} / \mathrm{L})$ and subjected to the covalent conversion by heating. As a typical example, the polymer assembly $(\mathbf{1 a} / \mathbf{2 a}$ $31 \mathrm{mg})$ was dissolved in $300 \mathrm{~mL}$ of THF $(0.1 \mathrm{~g} / \mathrm{L})$ and heated at $66^{\circ} \mathrm{C}$ for $5 \mathrm{~h}$ (at $110{ }^{\circ} \mathrm{C}$ for $30 \mathrm{~h}$ for $\mathbf{1 b} / \mathbf{2 a}$ ). The reaction 


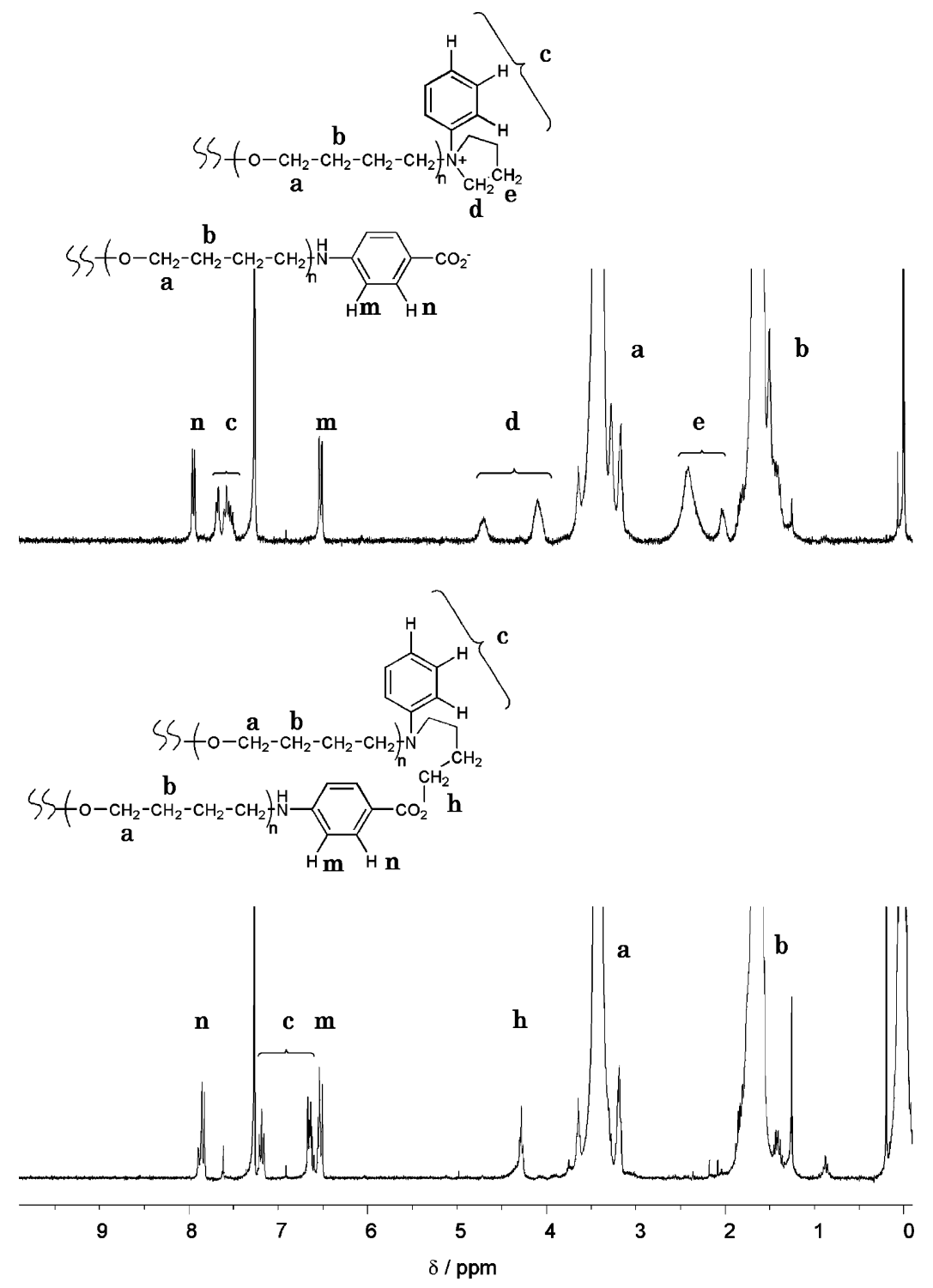

Figure 1. $300 \mathrm{MHz}{ }^{1} \mathrm{H}$ NMR spectra of the electrostatic self-assembly product from a poly(THF) having pyrrolidinium end groups (1a) and a poly(THF) having carboxylate end groups (2a) before (top), and the covalent conversion product (3a) by heat treatment (bottom) $\left(\mathrm{CDCl}_{3}, 40{ }^{\circ} \mathrm{C}\right)$

solvent was removed by evaporation, and the product was subjected to the column chromatography on silica gel. (3a, 22.8 $\mathrm{mg}, 74 \%$ yield) In a similar manner, $\mathbf{3 b}$ (purified by silica gel TLC, 60\% yield) and 3c (purified by SEC fractionation, 80\% yield) were obtained from $\mathbf{1} \mathbf{a} / \mathbf{2} \mathbf{b}$ and $\mathbf{1} \mathbf{b} / \mathbf{2 a}$, respectively. SEC fractionation was performed by means of JAI Model LC-908W apparatus with a refractive index detector Model RI-5, and with a column set of JAIGEL-2H and JAIGEL-3H. The eluent was THF at a flow rate of $3.5 \mathrm{~mL} / \mathrm{min}$. A stabilizer for the SEC eluent, i.e., 2,6-di-tert-butyl-4-methylphenol, was removed by precipitation of the product into petroleum ether cooled at $-78{ }^{\circ} \mathrm{C}$.

3a: ${ }^{1} \mathrm{H} \mathrm{NMR}\left(300 \mathrm{MHz} \mathrm{CDCl}_{3}\right): \delta 1.20-2.00\left(\mathrm{~m}, \mathrm{CH}_{2} \mathrm{CH}_{2} \mathrm{O}\right)$, 3.15-3.75 (m, $\left.\mathrm{CH}_{2} \mathrm{CH}_{2} \mathrm{O}\right), 4.28\left(\mathrm{t}, 4 \mathrm{H}, \mathrm{CO}_{2} \mathrm{CH}_{2}\right), 6.54(\mathrm{t}, J=$ $8.7 \mathrm{~Hz}, 4 \mathrm{H}, \mathrm{Ar}-\mathrm{H}$ meta to $\left.\mathrm{CO}_{2}\right), 6.60-6.82(\mathrm{~m}, 6 \mathrm{H}, \mathrm{NPh} o, p-$ $H$ ), 7.15-7.22 (m, 4H, NPh $m-H), 7.86$ (t, $J=8.7 \mathrm{~Hz}, 4 \mathrm{H}, \mathrm{Ar}-H$ ortho to $\mathrm{CO}_{2}$ ). IR: $1705 \mathrm{~cm}^{-1}$ (ester carbonyl).

3b: ${ }^{1} \mathrm{H} \mathrm{NMR}\left(300 \mathrm{MHz} \mathrm{CDCl}_{3}\right): \delta 1.30-1.85\left(\mathrm{~m}, \mathrm{CH}_{2} \mathrm{CH}_{2} \mathrm{O}\right)$, $3.10-3.70\left(\mathrm{~m}, \mathrm{CH}_{2} \mathrm{CH}_{2} \mathrm{O}\right), 4.33\left(\mathrm{t}, J=6.3 \mathrm{~Hz}, 4 \mathrm{H}, \mathrm{CO}_{2} \mathrm{CH}_{2}\right)$, 6.58-6.70 (m, 6H, NPh o,p-H), 7.10-7.20 (m, 4H, NPh $m-H)$, $7.38(\mathrm{~s}, 2 \mathrm{H}, \mathrm{Ar}-\mathrm{H}$ ortho to $\mathrm{NH}), 7.94(\mathrm{~s}, 1 \mathrm{H}, \mathrm{Ar}-\mathrm{H}$ para to $\mathrm{NH})$. IR: $1720 \mathrm{~cm}^{-1}$ (ester carbonyl).

3c: ${ }^{1} \mathrm{H}$ NMR $\left(300 \mathrm{MHz} \mathrm{CDCl}_{3}\right): \delta 1.20-2.35\left(\mathrm{~m}, \mathrm{CH}_{2} \mathrm{CH}_{2} \mathrm{O}\right.$, $\left.\mathrm{NCH}_{2} \mathrm{CH}_{2}\right), 3.10-3.85\left(\mathrm{~m}, \mathrm{CH}_{2} \mathrm{CH}_{2} \mathrm{O}\right), 3.96(\mathrm{~d}, J=5.4 \mathrm{~Hz}, 4 \mathrm{H}$,
$\left.\mathrm{CH}_{2}=\mathrm{CHCH}_{2}\right), 4.20-4.32\left(\mathrm{~m}, 4 \mathrm{H}, \mathrm{CO}_{2} \mathrm{CH}_{2}\right), 5.10-5.32(\mathrm{~m}, 4 \mathrm{H}$, $\left.\mathrm{CH}_{2}=\mathrm{CHCH}_{2}\right), 5.80-5.96\left(\mathrm{~m}, 2 \mathrm{H}, \mathrm{CH}_{2}=\mathrm{CHCH}_{2}\right), 6.54(\mathrm{t}, \mathrm{J}=$ $5.7 \mathrm{~Hz}, 4 \mathrm{H}, \mathrm{Ar}-\mathrm{H}$ meta to $\left.\mathrm{CO}_{2}\right), 7.85(\mathrm{t}, J=9.0 \mathrm{~Hz}, 4 \mathrm{H}, \mathrm{Ar}-H$ ortho to $\mathrm{CO}_{2}$ ). IR: $1705 \mathrm{~cm}^{-1}$ (ester carbonyl).

Measurements. Size exclusion chromatography (SEC) measurements were performed using a Tosoh model CCPS equipped with a refractive index detector model RI 8020 and a UV detector model UV 8020 at $254 \mathrm{~nm}$. A column of either TSK G3000HXL (300 $\mathrm{mm} \times 7.8 \mathrm{~mm}$ i.d., $5 \mu \mathrm{m}$ average particle size) or TSK G4000HXL ( $300 \mathrm{~mm} \times 7.8 \mathrm{~mm}$ i.d., $5 \mu \mathrm{m}$ average particle size) were employed with THF or THF $/ N, N, N^{\prime}, N^{\prime}$ tetramethylethylenediamine (TMEDA) $=90: 10$ as an eluent at a flow rate $1.0 \mathrm{~mL} / \mathrm{min}$ at $40{ }^{\circ} \mathrm{C}$. In a typical procedure, $40 \mu \mathrm{L}$ of sample solution (sample concentration of $0.5 \mathrm{wt} \%$ ) was injected. IR spectra were taken on a JASCO FT/IR-410 infrared spectrometer by casting the sample from a chloroform solution on a $\mathrm{NaCl}$ plate. ${ }^{1} \mathrm{H}$ NMR spectra were recorded on a JEOL JNM-AL300 apparatus in $\mathrm{CDCl}_{3}$. The proton chemical shift (ppm) was referenced to the signal of tetramethylsilane. MALDI-TOF mass spectra were taken on a Shimadzu AXIMA-CFR mass spectrometer. The spectrometer was equipped with a nitrogen laser $(\lambda=337 \mathrm{~nm})$ and with pulsed ion extraction. The operation was performed at an accelerating potential of $20 \mathrm{kV}$ by a linear positive ion mode. The sample 
polymer solution $(1 \mathrm{~g} / \mathrm{L})$ was prepared in THF. The matrix, 1,8-dihydroxy-9(10H)-anthracenone (dithranol, Aldrich) and sodium trifluoroacetate (Aldrich), was dissolved in THF (10 and $1 \mathrm{~g} / \mathrm{L}$, respectively). The polymer solution $(50 \mu \mathrm{L})$ was then mixed with $50 \mu \mathrm{L}$ of the matrix solution. A $1 \mu \mathrm{L}$ portion of the final solution was deposited onto a sample target plate and allowed to dry in air at room temperature. Mass values were calibrated by the three-point method with insulin plus $\mathrm{H}^{+}$at 5734.62 , insulin $\beta$ plus $\mathrm{H}^{+}$at 3497.96 and $\alpha$-cyanohydroxycinnamic acid dimer plus $\mathrm{H}^{+}$at 379.35 .

\section{Results and Discussion}

Electrostatic Self-Assembly and Covalent Fixation with Cationic and Anionic Telechelic Precursors. 1. Synthesis of a Ring Polymer. To obtain basic insights in the electrostatic self-assembly and covalent fixation process involving cationic and anionic telechelic precursors under dilution, we have first carried out a prototype reaction by using a telechelic poly(THF) precursor having cyclic ammonium salt groups (1a) and another having carboxylate end groups $(\mathbf{2 a})$.

A linear poly $(\mathrm{THF})\left(M_{\mathrm{p}}(\mathrm{SEC})=5500\right)$ having $N$ phenylpyrrolidinium salt end groups (1a) initially carrying trifluoromethansulufonate (triflate) counteranions, and a telechelic poly $(\mathrm{THF})\left(M_{\mathrm{p}}(\mathrm{SEC})=4400\right)$ having carboxylate end groups (2a) initially carrying tetrabutylammonium countercations were thus synthesized (Scheme 3). A THF solution containing an equimolar amount of $\mathbf{1 a}$ and $\mathbf{2 a}$ was then prepared by monitoring with ${ }^{1} \mathrm{H}$ NMR and was precipitated into ice-cooled water to remove tetra- $n$-butylammonium trifluoromethane sulfonate. An electrostatic polymer-polymer assembly (1a/2a) was recovered by simple filtration, and its $\mathrm{THF}$ solution was subjected to the heat treatment at $66{ }^{\circ} \mathrm{C}$ for $5 \mathrm{~h}$ under various dilutions $(0.1-1.0 \mathrm{~g} / \mathrm{L})$. SEC (S-Figure 5 in Supporting Information) showed that a product having narrow size distribution was exclusively formed along with the dilution. A covalently linked product (3a) was obtained in $74 \%$ yield after purification even at high dilution of $0.1 \mathrm{~g} / \mathrm{L}$ (Scheme 4).

The ${ }^{1} \mathrm{H}$ NMR comparison of the ionically self-assembled 1a/2a and the covalently converted $\mathbf{3 a}$ (Figure 1) showed that the signals attributed to the $N$-phenylpyrrolidinium salt group of $\mathbf{1 a} / \mathbf{2 a}$ at $1.98-2.08,2.10-$ $2.72,4.03-4.20,4.65-4.75$, and $7.50-7.75 \mathrm{ppm}$ are replaced by a triplet signal at $4.28 \mathrm{ppm}$ arising from ester methylene protons and signals at 6.60-6.82 and 7.15-7.22 ppm arising from the $N$-phenyl protons on the aminoester group. Aromatic protons due to 4 -aminobenzoate anion/ester groups are visible at 6.53/6.54 and 7.95/7.86 ppm. IR analysis also showed the formation of ester groups $\left(1705 \mathrm{~cm}^{-1}\right)$ in $\mathbf{3 a}$ after the heating treatment of $\mathbf{1} \mathbf{a} / \mathbf{2} \mathbf{a}$.

The obtained ring poly(THF), 3a, was further characterized by MALDI TOF mass spectroscopy (Figure 2). The spectrum of $\mathbf{3 a}$ showed a uniform series of peaks corresponding to poly(THF) with the peak interval of 72 mass units, and each peak corresponds exactly to the molecular mass summing up the linking structure produced by the covalent conversion reaction of the electrostatic polymer self-assembly, 1a/2a. As an example, the peak at 7190.05 (assumed to be the adduct with $\mathrm{Na}^{+}$) corresponds to the product with the number of THF unit $\left(\mathrm{DP}_{n}\right)$ of $90,\left(\mathrm{C}_{4} \mathrm{H}_{8} \mathrm{O}\right) \times 90+\mathrm{C}_{42} \mathrm{H}_{52} \mathrm{~N}_{4} \mathrm{O}_{4}$, plus $\mathrm{Na}^{+}$as 7189.546 .

SEC measurements of the ring poly(THF) $\mathbf{3 a}$, together with the linear precursor analogues of $1 \mathbf{a}$ and $\mathbf{2 a}$ (Figure 3) showed that 3a possesses distinctively higher appar-

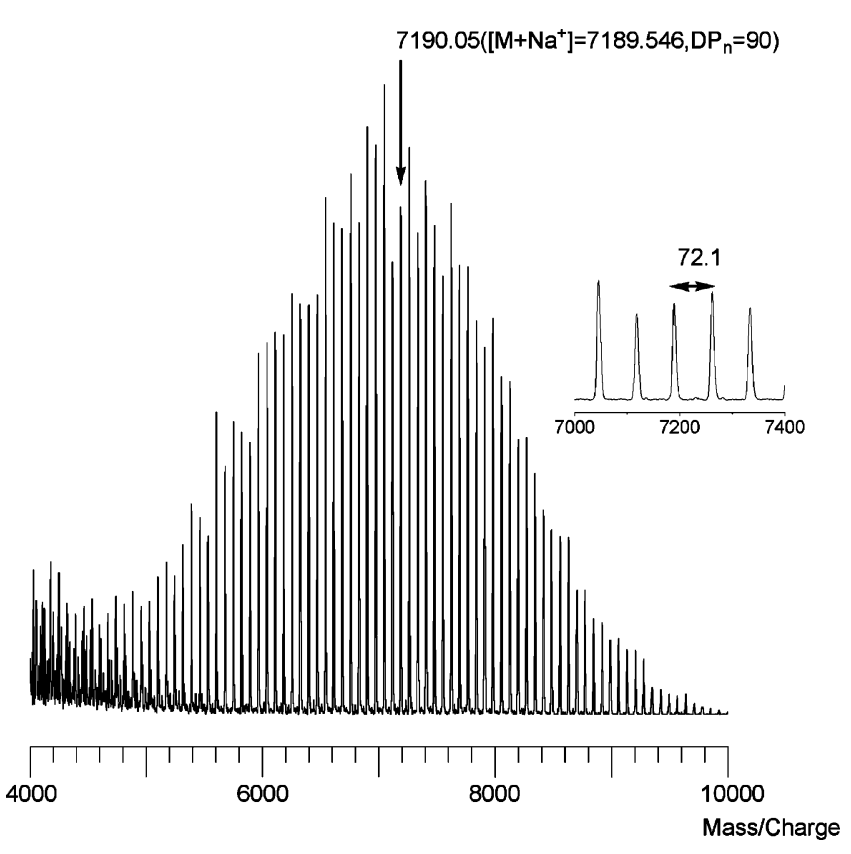

Figure 2. A MALDI-TOF mass spectrum of a ring poly(THF) (3a) (linear mode, matrix: dithranol with sodium trifluoroacetate).

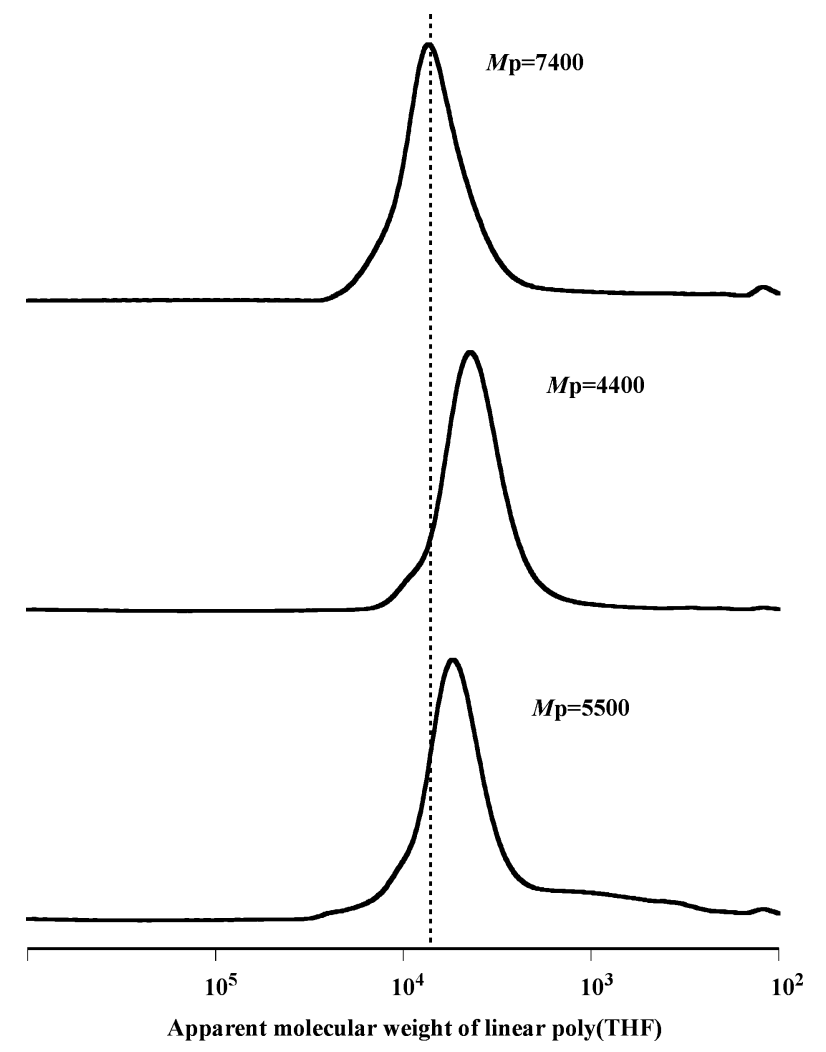

Figure 3. SEC traces (RI) of a ring poly(THF) (3a) (top), an anionic poly(THF) precursor analogue (2a with methyl ester end groups) (middle), and a cationic poly(THF) precursor analogue (1a with end groups ring-opened by benzoate anion) (bottom) (TSK G3000HXL, eluent: THF, $1.0 \mathrm{~mL} / \mathrm{min}$ ).

ent molecular weight $\left(M_{\mathrm{p}}=7400, \mathrm{PDI}=1.21\right)$ than each of the precursor analogues $\left(M_{\mathrm{p}}(\mathbf{1 a})=5500\right.$ and $\left(M_{\mathrm{p}}(\mathbf{2 a})\right.$ $=4400$ ). Moreover, the ring structure of 3a having a constricted hydrodynamic volume was evidenced by the apparent molecular weight of $\mathbf{3 a}\left(M_{\mathrm{p}}=7400\right)$ being noticeably smaller than its calculated molecular weight (9900), i.e., the sum of those of $\mathbf{1 a}$ and $\mathbf{2 a}$. The ratio of 


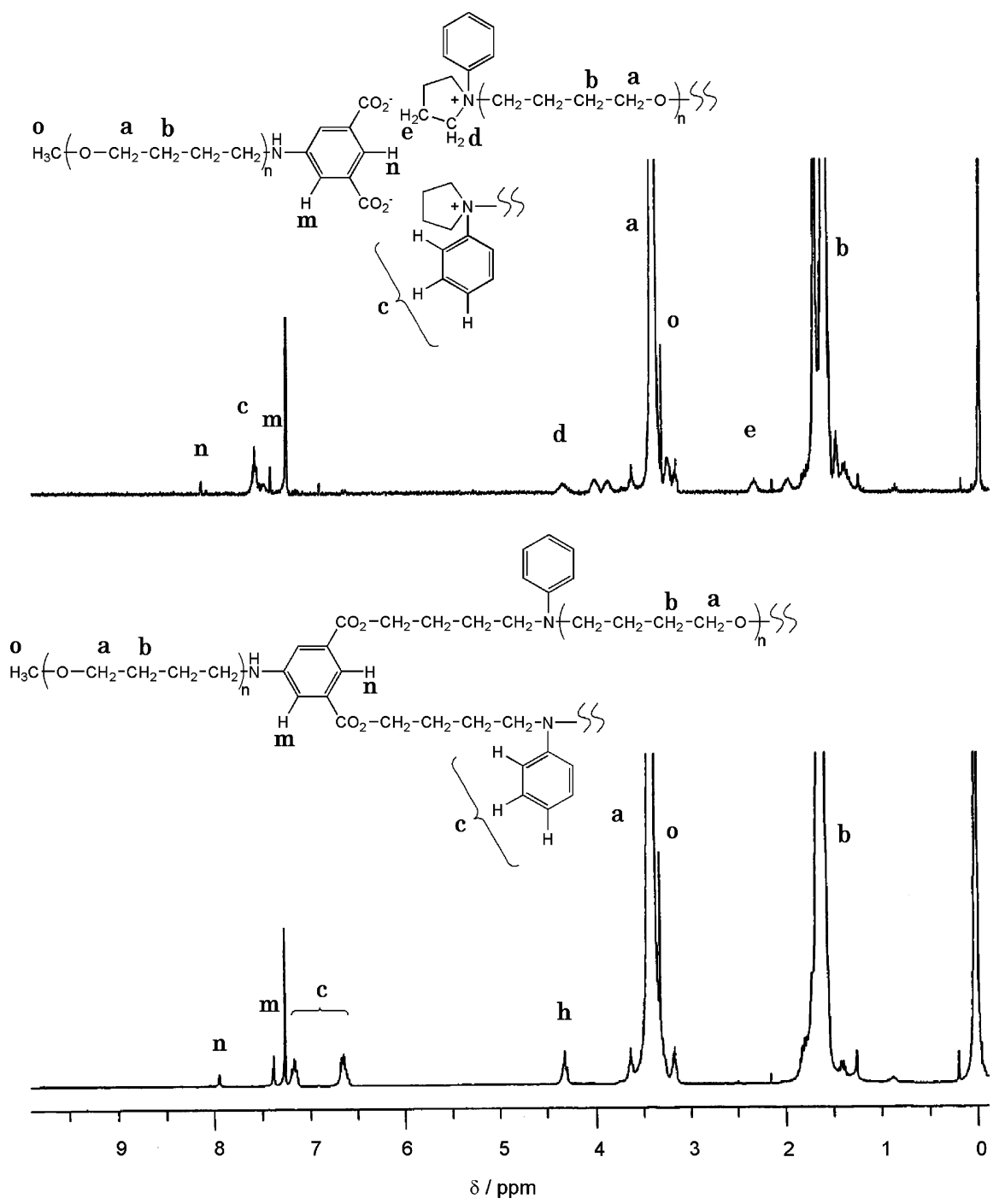

Figure 4. $300 \mathrm{MHz}^{1} \mathrm{H}$ NMR spectra of the electrostatic self-assembly product from a poly(THF) having pyrrolidinium end groups (1a) and a poly(THF) having a dicarboxylate end groups (2b) (top), and the covalent conversion product (3b) by heat treatment (bottom) $\left(\mathrm{CDCl}_{3}, 40{ }^{\circ} \mathrm{C}\right)$.

the apparent molecular weight, the measure of the hydrodynamic volume, of ring polymer $\mathbf{3 a}$ against the linear polymer analogue possessing the same molecular weight was 0.75 , and this value agrees with the reported ones $(0.68-0.81){ }^{24-26,40-44}$

These results clearly show that a ring polymer products was produced effectively through the electrostatic polymer self-assembly $\mathbf{1 a} / \mathbf{2 a}$, in which cations and anions balance the charges. It is remarkable that the covalent conversion proceeded effectively with polymeric carboxylate counteranions as in the previous small carboxylate anions, even under dilution.

Electrostatic Self-Assembly and Covalent Fixation with Cationic and Anionic Telechelic Precursors. 2. Synthesis of a Tadpole Polymer. We have then applied the electrostatic self-assembly process with cationic and anionic telechelic precursors for the preparation of a simplest tadpole polymer having a loop and a branch segments. Thus, a poly $(\mathrm{THF})\left(M_{\mathrm{p}}(\mathrm{SEC})=\right.$ 2800) having a dicarboxylate group at a single chain end $(\mathbf{2 b})$ initially carrying tetra- $n$-butylammonium countercations was newly synthesized (Scheme 3) and subjected to the reaction with a cationic counterpart (1a, $\left.M_{\mathrm{p}}(\mathrm{SEC})=5600\right)$. An electrostatic polymer assembly (1a/2b) was subsequently prepared by a similar proce- dure as for 1a/2a, detailed in the preceding section. The heat treatment of $\mathbf{1 a} / \mathbf{2 b}$ was carried out at $66{ }^{\circ} \mathrm{C}$ for 3 $\mathrm{h}$ under dilution at $0.2 \mathrm{~g} / \mathrm{L}$ in THF. A covalently linked product (3b) was obtained in $60 \%$ yield after purification by silica gel TLC (Scheme 4).

The ${ }^{1} \mathrm{H}$ NMR comparison of the ionically self-assembled $\mathbf{1 a} / \mathbf{2} \mathbf{b}$ and the covalently converted $\mathbf{3 b}$ (Figure 4) showed again that the signals attributed to the $N$-phenylpyrrolidinium salt group in $\mathbf{1 a} / \mathbf{2 b}$ at $1.93-$ $2.05,2.30-2.40,3.94-4.10,4.25-4.49$, and $7.45-7.70$ ppm are replaced by a triplet signal at $4.33 \mathrm{ppm}$ arising from ester methylene protons and signals at 6.58-6.70 and 7.10-7.20 ppm arising from the $N$-phenyl protons on the aminoester group. Aromatic protons due to isophthalate anion/ester group are visible at 7.42/7.38 and 8.14/7.94 ppm. IR analysis also showed the formation of ester groups $\left(1720 \mathrm{~cm}^{-1}\right)$ in $\mathbf{3 b}$ after the heating treatment of $\mathbf{1} \mathbf{a} / \mathbf{2} \mathbf{b}$.

SEC measurements of the tadpole poly(THF), 3b, together with the linear precursor analogues of $\mathbf{1 a}$ and $\mathbf{2 b}$ (Figure 5), showed that $\mathbf{3 b}$ possesses noticeably higher apparent molecular weight $\left(M_{\mathrm{p}}=6400\right.$, PDI $=$ 1.22) than those of each of the precursor analogues $\left(M_{\mathrm{p}}(\mathbf{1 a})=5600\right.$ and $\left(M_{\mathrm{p}}(\mathbf{2 a})=2800\right)$. Moreover, a loopcontaining structure of $\mathbf{3 b}$ with a constricted hydrody- 


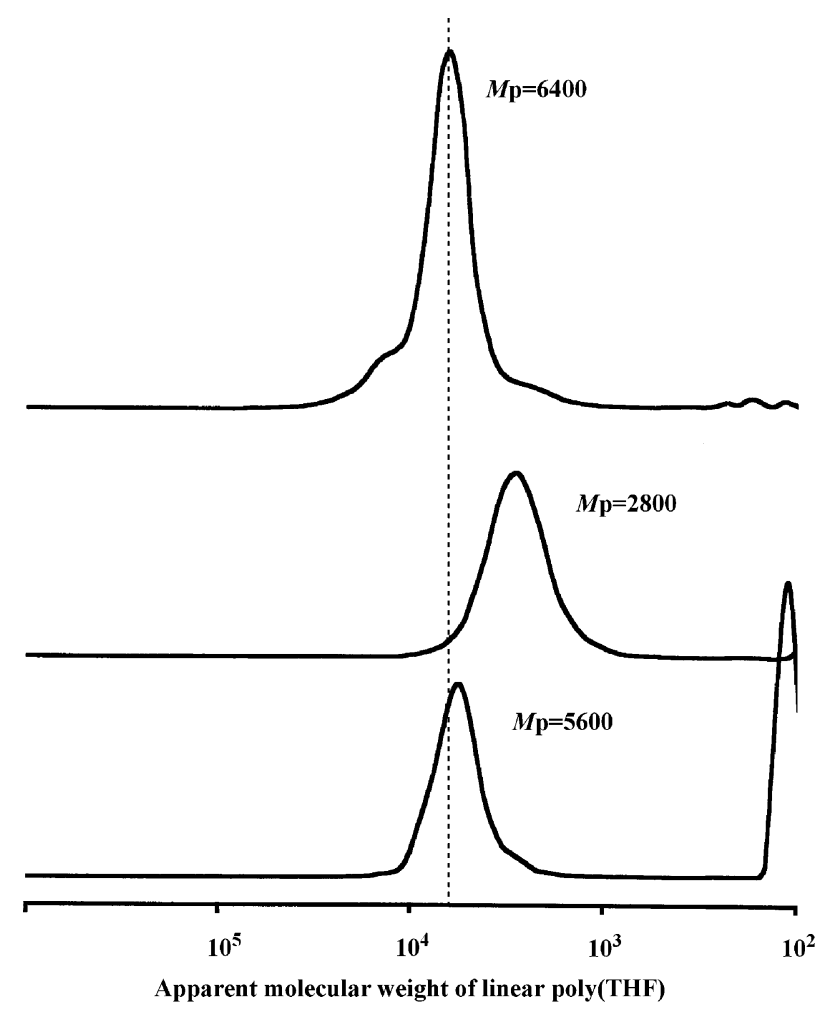

Figure 5. SEC traces (RI) of a tadpole poly(THF) (3b) (top), an anionic poly(THF) precursor analogue (2b with a methyl ester end group) (middle), and a cationic poly(THF) precursor analogue (1a with end groups ring-opened by benzoate anion) (bottom) (TSK G3000HXL, eluent: THF, $1.0 \mathrm{~mL} / \mathrm{min}$ ).

namic volume was evidenced by the apparent molecular weight of $\mathbf{3 b}\left(M_{\mathrm{p}}=6400\right)$ being distinctively smaller than its calculated molecular weight (8400), i.e., the sum of those of $\mathbf{1 a}$ and $\mathbf{2 b}$. The ratio of the apparent molecular weight, the measure of the hydrodynamic volume, of tadpole polymer $\mathbf{3 b}$ against the linear polymer analogue possessing the same molecular weight was 0.76 . We consider that this value is comparable with the reported one $(0.83)^{34}$ for the tadpole polymer having the relevant loop and branch segment length because the detailed chemical structures, i.e., the number and position of the polar aminoester linking groups, are different each other. The value could also be regarded marginally larger than the relevant ratio $(0.75)$ between the ring and the linear polymers having similar chemical structures observed in the preceding section.

These results show that a tadpole polymer was also produced effectively through the electrostatic polymer self-assembly, $\mathbf{1 a} / \mathbf{2} \mathbf{b}$, in which the two carboxylate anions in $\mathbf{2 b}$ are located close to each other at a single chain end of the polymer segment. The covalent conversion with such a polymeric carboxylate counteranion proceeded as effectively as in the previous cases involving $\mathbf{2 a}$ or small carboxylate anions. ${ }^{37}$

Electrostatic Self-Assembly and Covalent Fixation with Cationic and Anionic Telechelic Precursors. 3. Synthesis of a Two-Tail Tadpole Polymer. A two-tail tadpole polymer assembly is obtainable by two-sets of a bifunctional and a monofunctional cationic precursors with a trifunctional end-linking counteranion (Scheme 5). Upon dilution, however, it will be converted into a simple tadpole assembly composed of a one-set of the two polymeric components and a counteranion, in which cations and anions balance the charges. Thus, a two-tail tadpole polymer is not expected to be produced
Scheme 5. Dilution-Directed Tadpole Polymer Formation with Cationic and Anionic Telechelic Precursors

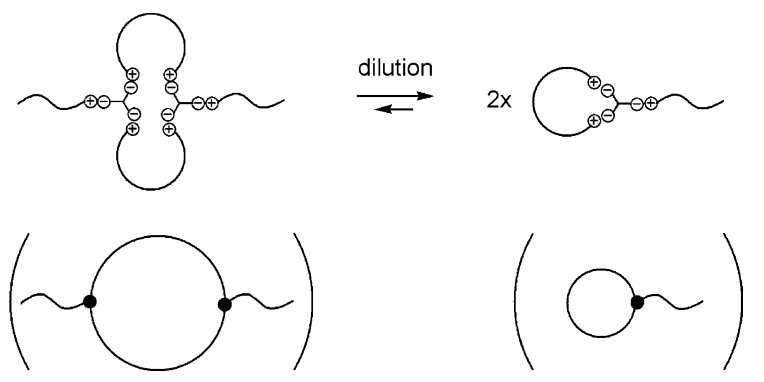

by the dilution of an electrostatically self-assembled polymer precursor carrying small counteranions. Another tadpole construction having a loop and two branches, i.e., a twin-tail tadpole polymer (Scheme 1), was obtained, on the other hand, from an interiorly functionalized precursor (1b) carrying a bifunctional small carboxylate counteranion. ${ }^{37}$

To achieve a one-step construction of a two-tail tadpole polymer topology, we have synthesized a poly$(\mathrm{THF})\left(M_{\mathrm{p}}(\mathrm{SEC})=8400\right)$ having two cyclic ammonium salt groups at interior positions (1b) and subjected to the reaction with a telechelic precursor having carboxylate groups $\left(\mathbf{2 a}, M_{\mathrm{p}}(\mathrm{SEC})=2500\right)$ (Scheme 3$)$. An electrostatic polymer assembly (1)/2a) was prepared in a similar manner as shown in the previous sections, i.e., the coprecipitation of a THF solution containing an equimolar amount of $\mathbf{1 b}$ and $\mathbf{2 a}$ into ice-cooled water. The subsequent heat treatment of $\mathbf{1 b} / \mathbf{2 a}$ was carried out in toluene at $110{ }^{\circ} \mathrm{C}$ for $30 \mathrm{~h}$ under dilution at $5.0 \mathrm{~g} / \mathrm{L}$. The covalent conversion reaction required a higher temperature and a longer reaction time with the use of 1b, having less reactive dialkylammonium salt groups in comparison with phenylalkylammonium salt groups in $1 a^{37}$ On the other hand, the dilution at $5.0 \mathrm{~g} / \mathrm{L}$ was sufficient to form an assembly consisting of one set of $\mathbf{1 b}$ and 2a. A covalently linked product (3c) was thus obtained in $80 \%$ yield after purification by SEC fractionation (Scheme 4).

The ${ }^{1} \mathrm{H}$ NMR comparison of the ionically self-assembled $\mathbf{1 b} / \mathbf{2 a}$ and the covalently converted 3c (Figure 6 ) showed again that the signals due to the dialkylpyrrolidinium salt group of $\mathbf{1 b} / \mathbf{2 a}$ at $2.45-2.63 \mathrm{ppm}$ are replaced by a signal at 4.20-4.32 ppm due to ester methylene protons. Aromatic protons from 4-aminobenzoate anion/ester groups are visible at 6.53/6.54 and $7.87 / 7.85 \mathrm{ppm}$, together with branch-end allyl group protons at around 5-6 ppm. IR analysis also showed the formation of ester groups $\left(1705 \mathrm{~cm}^{-1}\right)$ in $3 \mathbf{c}$ after the heating treatment of $\mathbf{1} \mathbf{b} / \mathbf{2 a}$.

The covalent fixation product, 3c, was examined also by MALDI-TOF mass spectroscopy (Figure 7). Despite the fact that the effective ionization of the higher molecular weight polymer products could not be achieved under the applied conditions, we could obtain the spectrum, showing a uniform series of peaks corresponding to poly(THF) with the peak interval of 72 mass units, and each peak corresponds exactly to the molecular mass summing up the linking structure produced by the covalent conversion reaction of the electrostatic polymer self-assembly, 1b/2a. As an example, the peak at 4376.41 (assumed to be the adduct with $\mathrm{Na}^{+}$) corresponds to the product with the number of THF unit $\left(\mathrm{DP}_{n}\right)$ of $50,\left(\mathrm{C}_{4} \mathrm{H}_{8} \mathrm{O}\right) \times 50+\mathrm{C}_{44} \mathrm{H}_{68} \mathrm{~N}_{4} \mathrm{O}_{6}$, plus $\mathrm{Na}^{+}$as 4376.386 . 

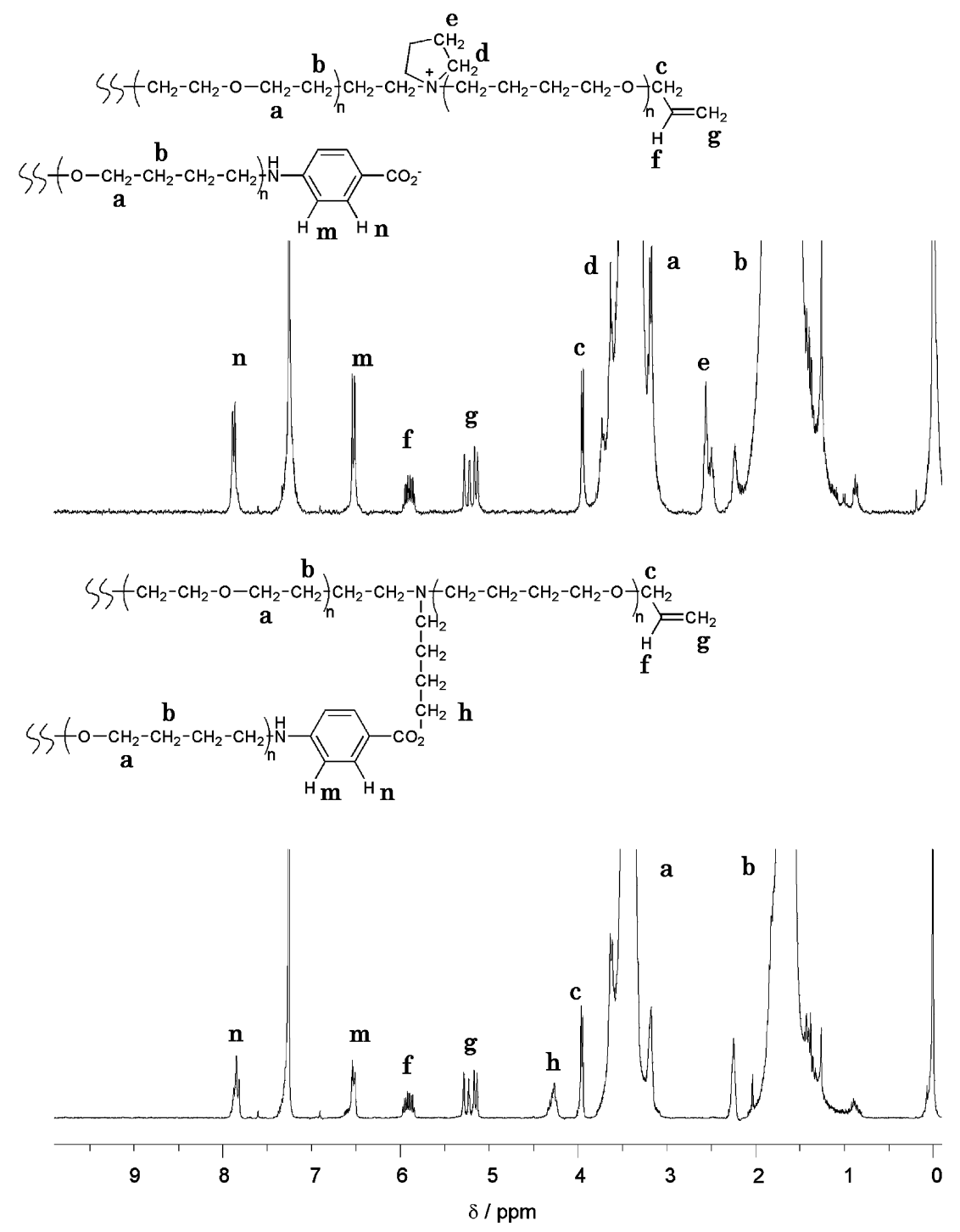

Figure 6. $300 \mathrm{MHz}{ }^{1} \mathrm{H}$ NMR spectra of the electrostatic self-assembly product from a poly(THF) having pyrrolidinium groups at interior positions (1b) and a poly(THF) having carboxylate end groups (2a) (top), and the covalent conversion product (3c) by heat treatment (bottom) $\left(\mathrm{CDCl}_{3}, 40{ }^{\circ} \mathrm{C}\right)$.

SEC measurements of the two-tail tadpole poly(THF), $\mathbf{3 c}$, together with the linear precursor analogues of $\mathbf{1 b}$ and $\mathbf{2 a}$ (Figure 8) showed that 3c possesses slightly higher apparent molecular weight $\left(M_{\mathrm{p}}=8600\right.$, PDI $=$ 1.13) than the cationic polymer precursor $\left(M_{\mathrm{p}}(\mathbf{1} \mathbf{b})=\right.$ 8400) even after the linking reaction with an anionic counterpart $\left(M_{\mathrm{p}}(\mathbf{2 a})=2500\right)$. This agrees with a loopcontaining structure of 3c having a constricted hydrodynamic volume, and the apparent molecular weight of 3c $\left(M_{\mathrm{p}}=8600\right)$ was noticeably smaller than its calculated molecular weight (10 900), i.e., the sum of those of $\mathbf{1 b}$ and $\mathbf{2 a}$. The ratio of the apparent molecular weight, i.e., the measure of the hydrodynamic volume, of the two-tail tadpole polymer, 3c, against the linear polymer analogue possessing the same molecular weight was 0.79 . This value is considered marginally larger than the relevant ones between the simple ring, 3a, and the tadpole, $\mathbf{3 b}$, having similar chemical structures $(0.75$ and 0.76 , respectively). It is also notable that a twintail tadpole showed the relevant ratio $(0.79-0.80)^{37}$ comparable with that for $3 \mathbf{c}$ having a two-tail tadpole structure.

These results show that a two-tail tadpole polymer was also produced effectively through the electrostatic polymer self-assembly, $\mathbf{1 b} / \mathbf{2 a}$, in which cyclic ammonium groups are located at interior positions along the polymer segment. Although the prolonged reaction was required to achieve the complete covalent conversion, a unique topological construction was produced in a high yield under moderate dilution.

\section{Conclusion}

An electrostatic self-assembly and covalent fixation process has been applied for the construction of a series of loop and branch polymer topologies by the combination of cationic telechelic polymers and anionic counterparts. A series of polymeric self-assemblies were prepared from cationic polymer precursors having two pyrrolidinium salt groups and anionic counterparts having two carboxylate groups. A ring (3a), a tadpole (3b, having one loop and one branch), and a twotail tadpole (3c, having one loop and two branches) polymers were obtained from polymeric self-assemblies, $\mathbf{1 a} / \mathbf{2 a}, \mathbf{1 a} / \mathbf{2} \mathbf{b}$, and $\mathbf{1} \mathbf{b} / \mathbf{2 a}$, respectively. The ratio of the hydrodynamic volumes for the respective loopcontaining polymers against the linear analogue was estimated by SEC, and the order of the three-dimensional size was a ring $<$ a tadpole $<$ a two-tail 


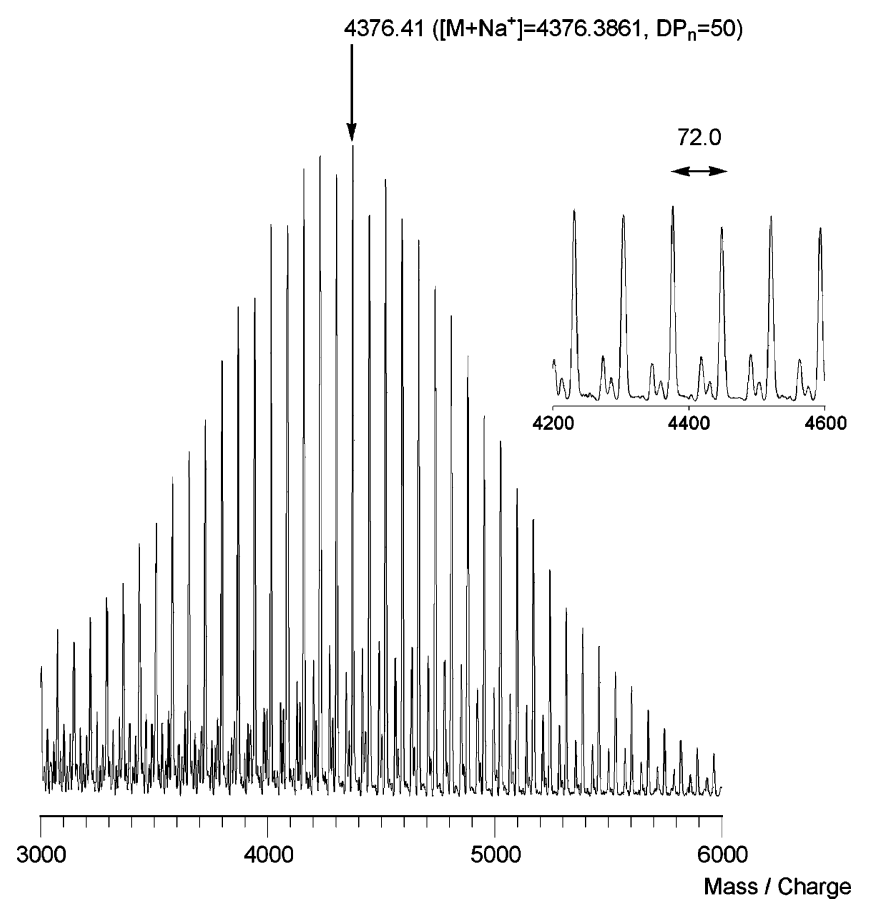

Figure 7. A MALDI-TOF mass spectrum of a two-tail tadpole poly(THF) (3c) (linear mode, matrix: dithranol with sodium trifluoroacetate).

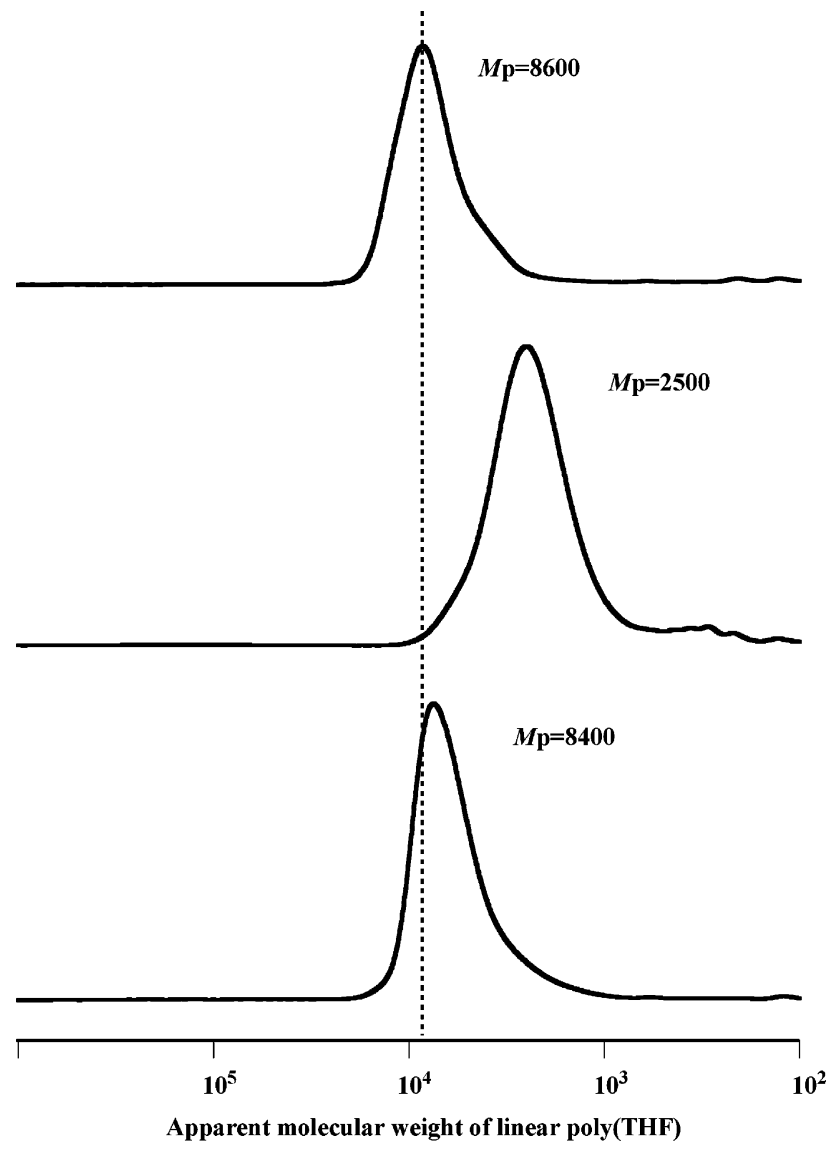

Figure 8. SEC traces (RI) of a two-tail tadpole poly(THF) (3c) (top), an anionic poly(THF) precursor analogue (2a with methyl ester end groups) (middle), and a cationic poly(THF) precursor analogue (1) with interior groups ring-opened by benzoate anion) (bottom) (TSK G4000HXL, eluent: THF/ TMEDA $=90: 10,1.0 \mathrm{~mL} / \mathrm{min}$ ).

tadpole < linear. This new process will be applicable for the construction of various more complex polymer topologies, and further studies are in progress in our laboratory.

Acknowledgment. Authors are grateful to Professor H. Oike (Tokyo University of Agriculture and Engineering) for his help in a part of this study, and to Professor M. Kakimoto for our access to the NMR apparatus. This work was supported partly by a grant from the Ministry of Education, Culture, Sports, Science, and Technology, Japan (17350054).

Supporting Information Available: ${ }^{1} \mathrm{H}$ NMR spectra of the precursors of $\mathbf{2 a}$ and of $\mathbf{2 b}$ (methyl esters and their hydrolyzed carboxylic acid derivatives), and SEC results of the covalent conversion products from $\mathbf{1 a} / \mathbf{2 a}$ under various dilutions. These materials are available free of charge via the Internet at http://pubs.acs.org.

\section{References and Notes}

(1) Geothals, E. J. Telechelic Polymers: Synthesis and Applications; CRC: Boca Raton, FL, 1989.

(2) Jérome, R.; Henrioulle-Granville, M.; Boutevin, B.; Robin, J. J. Prog. Polym. Sci. 1991, 16, 837-906.

(3) Vanhoorne, P.; Jérome, R. Contribution of Halato-telechelic Polymers to the Modeling of Morphology and Solution Properties of Ionomers. In Ionomers; Schlick, S., Ed.; CRC: Boca Raton, FL, 1996; pp 187-217.

(4) Ivan, B.; Feldthusen, J.; Müller, A. H. E. Macromol. Symp. 1996, 102, 81-90.

(5) Tezuka, Y. Telechelic Oligomers (with Cyclic Onium Salt Groups). In Polymeric Materials Encyclopedia; Salamone, J. C., Ed.; CRC: Boca Raton, FL, 1996; pp 8263-8268.

(6) Van Caeter, P.; Goethals, E. J. Trends Polym. Sci. 1995, 3, 227-233.

(7) Quirk, R. P.; Jang, S. H.; Yang, H.; Lee, Y. Macromol. Symp. 1998, 132, 281-291.

(8) Gaynor, S. G.; Matyjaszewski, K. ACS Symp. Ser. 1998, 685, 396.

(9) Hadjichristidis, N.; Pitskalis, M.; Pispas, S.; Iatrou, H. Chem. Rev. 2001, 101, 3747-3792.

(10) Hawker, C. J.; Wooley, K. L. Science 2005, 309, 1200-1205.

(11) Wu, P.; Feldman, A. K.; Nugent, A. K.; Hawker, C. J.; Scheel, A.; Voit, B.; Pyun, J.; Fréchet, J. M. J.; Sharpless, K. B.; Folkin, V. V. Angew. Chem., Int. Ed. 2004, 43, 3928-3933.

(12) Opsteen, J. A.; van Hest, C. M. Chem. Commun. 2005, 5759.

(13) Tezuka, Y. Prog. Polym. Sci. 1992, 17, 471-514.

(14) Tezuka, Y.; Shida, T.; Shiomi, T.; Imai, K.; Goethals, E. J. Macromolecules 1993, 26, 575-580.

(15) Tezuka, Y.; Hayashi, S. Macromolecules 1995, 28, 3038-3041.

(16) Tezuka, Y.; Imai, K.; Shiomi, T. Macromol. Chem. Phys. 1997, $198,627-641$.

(17) Tezuka, Y.; Iwase, T.; Shiomi, T. Macromolecules 1997, 30, $5220-5226$.

(18) Tezuka, Y.; Murakami, Y.; Shiomi, T. Polymer 1998, 39 2973-2976.

(19) Tezuka, Y. Chem. Rec. 2005, 5, 17-26.

(20) Tezuka, Y. J. Polym. Sci., Part A: Polym. Chem. 2003, 41, $2905-2917$.

(21) Tezuka, Y.; Oike, H. Prog. Polym. Sci. 2002, 27, 1069-1122.

(22) Tezuka, Y.; Oike, H. Macromol. Rapid Commun. 2001, 22, $1017-1029$

(23) Oike, H.; Imaizumi, H.; Mouri, T.; Yoshioka, Y.; Uchibori, A.; Tezuka, Y. J. Am. Chem. Soc. 2000, 122, 9592-9599.

(24) Oike, H.; Mouri, T.; Tezuka, Y. Macromolecules 2001, 34, $6592-6600$

(25) Oike, H.; Hamada, M.; Eguchi, S.; Danda, Y.; Tezuka, Y. Macromolecules 2001, 34, 2776-2782.

(26) Tezuka, Y.; Mori, K.; Oike, H. Macromolecules 2002, 35, $5707-5711$

(27) Oike, H.; Mouri, T.; Tezuka, Y. Macromolecules 2001, 34, $6229-6234$

(28) Oike, H.; Kobayashi, S.; Mouri, T.; Tezuka, Y. Macromolecules 2001, 34, 2742-2744.

(29) Tezuka, Y.; Tsuchitani, A.; Yoshioka, Y.; Oike, H. Macromolecules 2003, 36, 65-70.

(30) Tezuka, Y.; Tsuchitani, A.; Oike, H. Polym. Int. 2003, 52, $1579-1583$. 
(31) Tezuka, Y.; Tsuchitani, A.; Oike, H. Macromol. Chem., Rapid Commun. 2004, 25, 1531-1535.

(32) Tezuka, Y.; Fujiyama, K. J. Am. Chem. Soc. 2005, 127, 62666270 .

(33) Tezuka, Y.; Oike, H. J. Am. Chem. Soc. 2001, 123, 1157011576.

(34) Oike, H.; Uchibori, A.; Tsuchitani, A.; Kim, H.-K.; Tezuka, Y. Macromolecules 2004, 37, 7595-7601.

(35) Beinat, S.; Schappacher, M.; Deffieux, A. Macromolecules 1996, 29, 6737-6743.

(36) Kubo, M.; Hayashi, T.; Kobayashi, H.; Itoh, T. Macromolecules 1998, 31, 1053-1057.

(37) Oike, H.; Washizuka, M.; Tezuka, Y. Macromol. Rapid Commun. 2001, 22, 1128-1134.

(38) The relevant topology, but having a shape-persistent, rigid ring component, see: Rosselli, S.; Ramminger, A.-D.; Wagner, T.; Silier, B.; Wiegand, S.; Häu $\beta$ ler, W.; Lieser, G.; Scheu- mann, V.; Höger, S. Angew. Chem., Int. Ed. 2001, 40, 31383141.

(39) The relevant topology, but having a small crown ether (18crown-6) ring component, see: Feng, X.-S.; Yan, L.-F.; Wen, J.; Pan, C.-Y. Polymer 2002, 43, 3131-3137.

(40) Roovers, J.; Toporowiski, P. M. Macromolecules 1983, 16, 843-849.

(41) Hogen-Esch, T. E.; Sundararajan, J.; Toreki, W. Makromol. Chem., Macromol. Symp. 1991, 47, 23-42.

(42) Rique-Lurbet, L.; Schappacher, M.; Deffieux, A. Macromolecules 1994, 27, 6318-6324.

(43) Deffieux, A.; Schappacher, M. Macromol. Symp. 1995, 95 , 103-119.

(44) Kubo, M.; Hayashi, T.; Kobayashi, H.; Tsuboi, K.; Itoh, T. Macromolecules 1997, 30, 2805-2807.

MA051980G 